\title{
Thyroid Dysfunction and Morphological Abnormalities in Patients with Type 1 Diabetes Mellitus
}

\author{
Heba-Allah Moustafa Kamal Al-Din ${ }^{1}$, Rokaya Abd-Al Aziz Mohamed ${ }^{1}$, Shereen Sadik El-Sawy ${ }^{1}$, \\ Noha Adly Sadik ${ }^{1,}$, Rasha Mohamed Abd EI Samie ${ }^{1}$, Mahmoud Ahmed Khatab ${ }^{2}$, \\ Laila Ahmed Rashed ${ }^{3}$
}

${ }^{1}$ Internal Medicine Department, Faculty of Medicine, Cairo University, Cairo, Egypt

${ }^{2}$ National Institute of Diabetes and Endocrinology, Cairo, Egypt

${ }^{3}$ Biochemistry Department, Faculty of Medicine, Cairo University, Cairo, Egypt

\section{Email address:}

noha_adly@yahoo.com (N. A. Sadik)

\section{To cite this article:}

Heba-Allah Moustafa Kamal Al-Din, Rokaya Abd-Al Aziz Mohamed, Shereen Sadik El-Sawy, Noha Adly Sadik, Rasha Mohamed Abd El Samie, Mahmoud Ahmed Khatab, Laila Ahmed Rashed. Thyroid Dysfunction and Morphological Abnormalities in Patients with Type 1 Diabetes Mellitus. American Journal of Internal Medicine. Vol. 3, No. 4, 2015, pp. 185-193. doi: 10.11648/j.ajim.20150304.16

\begin{abstract}
Background: Type 1 diabetes mellitus is an autoimmune disease. Several studies have documented great variations in the prevalence of thyroid dysfunction and autoimmune thyroid disease (AITD) in type 1 diabetic patients. Undiagnosed thyroid dysfunction has negative impact on the metabolic control and will aggravate the cardiovascular disorders. Objectives: We aimed to investigate the presence of thyroid dysfunction and the associated morphological abnormalities in type 1 diabetes mellitus. Methods: 80 type 1 diabetic patients without overt thyroid disease attending the outpatient clinic of diabetes at Kasr Al Aini hospital, faculty of medicine, Cairo University were enrolled in the study. Thyroid functions (TSH, FT4, FT3), anti thyroid peroxidase (anti-TPO) and anti thyroglobulin (anti-TG) antibodies were measured in all patients. Thyroid ultrasound was performed in all patients and in 50 healthy control subjects. The data was analyzed and expressed in terms of mean $\pm \mathrm{SD}$. Pearson correlation was performed to establish the relationship between different variables. Results: 52 of 80 patients $(65 \%)$ showed high TSH levels with mean $(12.37 \pm 3.9 \mathrm{mIU} / \mathrm{ml})$ and 25 patients $(31.3 \%)$ showed positive anti-TG anti-TPO levels with mean $(906 \pm 184.3,628 \pm 137.5 \mathrm{IU} / \mathrm{ml})$ respectively. The high TSH levels were statistically significantly associated with high anti-TG levels and anti-TPO levels with (mean $570.23 \pm 372.41,366.52 \pm 281.34 \mathrm{IU} / \mathrm{ml}$ ) respectively with P-value $<0.001$. There was significant increase in the gland volume in diabetic patients with mean $(3.4 \pm 1.5 \mathrm{ml})$ versus $(2.9 \pm 0.9 \mathrm{ml})$ in the control group, P-value $<0.046$. Also $25 \%$ of patients showed heterogenous hypoechogenic gland texture versus $6 \%$ in the control group which was statistically significantly different, P-value $=0.008$ and $50 \%$ of the patients showed increase in gland vascularity versus $12 \%$ in the control group which was statistically significantly different with P-value $<0.001$. These morphological abnormalities were associated with high (TSH, anti-TPO and anti-TG) levels but weren't significant. High TSH levels were strongly positively correlated with anti-TPO and anti-TG, $r=(0.84,0.83)$ respectively, P-value $<0.001$. Conclusions: Type 1 diabetic patients had high incidence of thyroid dysfunction and AITD associated with morphological abnormalities of the thyroid gland. So we recommend screening for thyroid dysfunction in all patients with type 1 DM to avoid additional cardiovascular risk factors.
\end{abstract}

Keywords: Type 1 Diabetes Mellitus, Thyroid Dysfunction, Thyroid Antibodies, AITD

\section{Introduction}

Type 1 diabetes mellitus is a chronic autoimmune disease due to autoimmune destruction of pancreatic beta cells which leads to insulin deficiency. It is commonly diagnosed in childhood but one-fourth of cases presents in adults [1]. Other autoimmune disorders have been reported with type 1 diabetes, such as thyroid disease, celiac disease, adrenal insufficiency, vitiligo, alopecia, and gastric autoimmunity [2]. Autoimmune thyroiditis is the most prevalent immunological disease in patients with type 1 diabetes. It is characterized by the production of auto antibodies against the thyroid gland with subsequent $\mathrm{T}$ lymphocytic infiltration which leads to development of thyroid gland dysfunction [3]. Autoimmune 
thyroiditis is often clinically silent but it may progress to autoimmune thyroid disease (AITD), recognized as overt or subclinical hypothyroidism or hyperthyroidism [4]. The prevalence of AITD among diabetic patients varies between 3 to $50 \%$ and there is increased incidence inside the family members, when compared to general population $[2,5]$. Previous studies have reported a prevalence of $1-5 \%$ for overt hypothyroidism and $0.5-7 \%$ for thyrotoxicosis in young type 1diabetic patients [2,6].

Unrecognized thyroid dysfunction has negative impact on metabolic control and will aggrravate the cardiovascular disease risk in diabetic patients [7]. Hypothyroidism may lead to recurrent attacks of hypoglycemia [8], growth retardation, increase body weight, dyslipidemia, and cardiovascular disorder in diabetic patients [9]. Hyperthyroidism affects the glucose metabolism and may worsen diabetic complications, leading to uncontrolled diabetes and increased susceptibility to diabetic ketoacidosis [10].

AITD is easily diagnosed by measuring thyroid circulating autoantibodies, these auto antibodies are directed against anti thyroperoxidase (anti-TPO) and anti thyroglobolin (anti-TG) [3]. Moreover, thyroid ultrasound is known to be an easy, non invasive method for evaluation of the gland morphology, volume, echogenicity and any thyroidal lesions [11]. An enlarged thyroid gland with heterogeneous echo pattern is a common ultrasound presentation in AITD [12]. The American Diabetes Association (ADA) recommended screening TSH after diagnosis of diabetes and then every one to two years. It also recommended that patients found to have positive anti-TPO antibodies with normal thyroid function tests should be screened more frequently every six months to a year [13].

The aim of our study was to investigate the presence of AITD and thyroid dysfunction and detect possible lesions in the gland structure using thyroid ultrasound in type I diabetic Egyptian patients.

\section{Patients and Methods}

\subsection{Subjects}

80 patients with type 1 diabetes who attended the outpatient clinic of diabetes and endocrinology, Kasr Al Aini Hospital, Cairo University and 50 healthy age matched control subjects were included in the study. All diabetic patients met the diagnostic criteria of the Expert Committee on the Diagnosis and Classification of Diabetes Mellitus [14] The study was performed from December 2013 to September 2014.

Exclusion criteria: Patients with Type 2 DM and Patients having symptoms or signs suggestive of thyroid disorders as hyperthyroidism, hypothyroidism or goiter were excluded.

Ethical aspects: Research protocols were approved by the medical ethics committee of Kasr Al Ainy medical school, Cairo University. All participants provided a written informed consent after the research protocols were carefully explained to them. Informed consent was obtained from all the study participants and their approval taken by signature.

\subsection{Procedures}

All subjects underwent a complete screening panel, including history taking, physical examination. Weight, height and blood pressure were recorded. Body mass index (BMI) was calculated. Thyroid ultrasound was performed in all subjects. Laboratory investigation included: hemoglobin A1C (HbAlc), serum thyroid stimulating hormone (TSH), serum free triiodothyronin (FT3), serum free thyroxin (FT4), and anti- thyroperoxidase (anti-TPO) and anti-thyroglobulin (anti-TG) antibodies.

HbA1c level was measured by a quantitative turbidimetric inhibition immunoassay (TINIA) method using DiminsionRxL Max. This was expressed as a percentage of the normal haemoglobin with standardized normal range, $4.3 \%$ to $5.8 \%$. The system and the used reagent were supplied by Dade Behring (Siemens Healthcare Diagnostics, Germany).

The DRG TSH ELISA kit is a solid phase enzyme-linked immunosorbent assay (ELISA) based on the sandwich principle [15]; the normal range of TSH was $(0.4-6 \mu \mathrm{IU} / \mathrm{ml})$. DRG FT3 (EIA-3801) (DRG International Inc., USA) is a solid phase competitive enzyme immunoassay for the quantitative measurement of FT3 in serum [16]; the normal range of FT3 was (1.4-4.2 $\mathrm{pg} / \mathrm{ml})$. The quantitative determination of FT4 concentration in human serum was done by a micro plate competitive enzyme immunoassay (DRG FT4 International Inc., USA) [17]; the normal range of FT4 was (0.8-1.9 ng/dl).

Immunometric Enzyme Immunoassay was done for the quantitative determination of antibodies against thyroglobulin (TG) and thyroid peroxidase (TPO) [18]. The upper normal limit of anti-TPO was $50 \mathrm{IU} / \mathrm{ml}$, values from $50-400 \mathrm{IU} / \mathrm{ml}$ were considered borderline and values $>400$ $\mathrm{IU} / \mathrm{ml}$ were considered positive. The upper normal limit of anti-TG was $100 \mathrm{IU} / \mathrm{ml}$, values from $100-600 \mathrm{IU} / \mathrm{ml}$ were considered borderline and values $>600 \mathrm{IU} / \mathrm{ml}$ were considered positive.

Thyroid ultrasound was done by HDI 5000 ultrasound system through probe L 7-4.

The definition and analyses of thyroid volumes, gland echogenicity and thyroid nodules were performed according to the method reported by Norbert et al [19].

The volume of each thyroid lobe was calculated with ellipsoid formula: Volume $(\mathrm{ml})=$ Length $(\mathrm{cm}) \times$ Width $(\mathrm{cm})$ $\mathrm{x}$ Thickness $(\mathrm{cm}) \mathrm{x} 0.5$. Total volume was obtained as the sum of two thyroid lobes. The isthmus was not included in the sum [20].

\subsection{Statistical Analysis}

Data was entered on the computer using "Microsoft Office Excel Software" program (2010) for windows, then transferred to the Statistical Package of Social Science Software program, version 21 (SPSS) to be statistically analyzed. Data was summarized using range, mean and 
standard deviation for quantitative variables or frequency and percentage for qualitative ones. Comparison between groups was performed using independent sample t-test or Mann Whitney test (if quantitative variables) and Chi square with Fisher's exact test (if qualitative ones). Pearson or Spearman correlation coefficients were calculated to signify the association between different quantitative variables parametric or non-parametric respectively. $\mathrm{P}$ values less than 0.05 were considered statistically significant, and less than 0.01 were considered highly significant.

\section{Results}

80 type 1 diabetic patients were 45 males and 35 females their age range between 13-37 years with mean $(22.0 \pm 5.3)$ years and the duration of diabetes range between $0.2-23$ years with mean $(7.8 \pm 5.3)$ years, their $\mathrm{HbAlc}$ mean $(10.4 \pm$ $2.3 \%)$, their BMI mean $\left(22.4 \pm 2.6 \mathrm{~kg} / \mathrm{m}^{2}\right)$. Table (1) shows the mean thyroid functions and antibodies in our type 1 diabetic patients.

Screening for thyroid dysfunction in our patients revealed elevated TSH levels in 52 patients out of 80 with mean $12.3 \pm 3.9 \mu \mathrm{IU} / \mathrm{ml}$ which represent $65 \%$ of all patients and only 28 patients had normal TSH levels with mean $3.9 \pm 0.99$ $\mu \mathrm{IU} / \mathrm{ml}$ (Table 2)

We found 25 of 80 patients $(31.3 \%)$ had positive anti-TG and anti-TPO Abs levels with mean $(906 \pm 184.3)(628+$ 137.5) IU/ml respectively and the rest of patients had either negative or borderline values (Table 3 )

There were statistically significant decrease in serum FT3 and FT4 levels and significant increase in anti-TG and antiTPO in patients with high TSH levels compared to patients with normal TSH levels, $\mathrm{P}<0.001$ (Table 4, Figs. 1, 2). There were not any significant differences in age, duration of diabetes and $\mathrm{HbAlc}$ in relation to differences in TSH levels (Table 4).

The differences between the number and percentage of males and females regarding different levels of TSH, Anti-
TPO and Anti TG Abs were not significant (Table 5).

We performed thyroid US in all patients and 50 subjects used as a control group they were 26 males and 24 females; their mean age was $23.7 \pm 5.4$ years, their BMI mean $(23.5 \pm$ $\left.2.9 \mathrm{~kg} / \mathrm{m}^{2}\right)$. There was statistically significant increase in the thyroid volume in our patients compared to controls, $\mathrm{P}=0.046$ (Table 6, Fig 3).

Thyroid US revealed morphological abnormalities in the form of increased thyroid gland texture heterogenecity and vascularity in type 1 diabetic patients compared to controls, $\mathrm{P}(0.008,<0.001)$ respectively and these abnormal morphological findings were present in $25 \%$ of patients and $6 \%$ in the control group which were statistically significant, $\mathrm{P}=0.008$ (Table 7, Figs. 4,5). The heterogenous texture and increased vascularity in patients with type $1 \mathrm{DM}$ were associated with higher mean levels of thyroid Abs and TSH than in patients with lower TSH and thyroid Abs but of no statistical significant value (Table 8). Our results showed strong positive correlation between thyroid antibodies and TSH, $\mathrm{P}<0.001$ and strong negative correlation with FT3 and FT4, $\mathrm{P}<0.001$ (Table 9, Fig 6, 7).

Table (1). Thyroid functions and antibodies in type 1 diabetic patients.

\begin{tabular}{ll}
\hline Parameter & Mean \pm SD \\
\hline Free T3 pg/ml & $1.62 \pm 0.82$ \\
Free T4 ng/dl & $1.12 \pm 0.63$ \\
TSH $\mu \mathrm{IU} / \mathrm{ml}$ & $9.42 \pm 5.15$ \\
Anti TG IU/ml & $383.9 \pm 394.5$ \\
Anti- TPO IU/ml & $205.2 \pm 281$ \\
\hline
\end{tabular}

Table (2). Frequency, percent and mean $\pm S D$ of TSH levels in patients with TIDM.

\begin{tabular}{lll}
\hline & Normal TSH & $\begin{array}{l}\text { Abnormal (High) } \\
\text { TSH }\end{array}$ \\
\hline Frequency & 28 & 52 \\
Percentage & $35 \%$ & $65 \%$ \\
Mean + SD & $3.9 \pm 0.99$ & $12.37 \pm 3.9$ \\
\hline
\end{tabular}

Values are expressed as frequency, percent and means \pm SD

Table (3). Anti-TG and Anti-TPO levels in type 1 diabetic patients.

\begin{tabular}{lllllll}
\hline & Anti-TG & & \multicolumn{3}{c}{ Anti- TPO } \\
\cline { 2 - 7 } & No & \% & Mean \pm SD & No & \% & Mean \pm SD \\
\hline Negative & 31 & $38.8 \%$ & $27.9 \pm 20.6$ & 32 & $40 \%$ & $15.4 \pm 8.6$ \\
Borderline & 24 & $30 \%$ & $299.8 \pm 155.3$ & 23 & $28.7 \%$ & $148.8 \pm 98.9$ \\
Positive & 25 & $31.3 \%$ & $906 \pm 184.3$ & 25 & $31.3 \%$ & $628 \pm 137.5$ \\
\hline
\end{tabular}

Values are expressed as frequency, percent and means $\pm \mathrm{SD}$

Table (4). Comparison of different parameters in type 1 diabetic patients according to TSH levels.

\begin{tabular}{llll}
\hline & High TSH & Normal TSH & P value \\
\cline { 2 - 3 } & $\mathbf{1 2 . 3 \pm 3 . 9}$ & $\mathbf{3 . 9} \pm \mathbf{0 . 9 9}$ & 0.3 \\
\hline Age $(\mathrm{yrs})$ & $21.52 \pm 5.74$ & $22.79 \pm 4.43$ & $7.72 \pm 6.06$ \\
Duration of DM (yrs) & $7.88 \pm 4.93$ & $10.06 \pm 2.58$ & 0.9 \\
HbA1c $\%$ & $10.51 \pm 2.19$ & $2.42 \pm 0.78$ & 0.4 \\
Free T3 $(\mathrm{pg} / \mathrm{ml})$ & $1.19 \pm 0.51$ & $1.78 \pm 0.43$ & $<0.001^{*}$ \\
Free T4 $(\mathrm{ng} / \mathrm{dl})$ & $0.76 \pm 0.37$ & $37.82 \pm 48.82$ & $<0.001^{*}$ \\
Anti -TG $(\mathrm{IU} / \mathrm{ml})$ & $570.23 \pm 372.41$ & $19.86 \pm 21.92$ & $<0.001^{*}$ \\
Anti-TPO $(\mathrm{IU} / \mathrm{ml})$ & $366.52 \pm 281.34$ & $3.45 \pm 1.27$ & $<0.001^{*}$ \\
Gland volume $(\mathrm{ml})$ & $3.33 \pm 1.61$ & & 0.7 \\
\hline
\end{tabular}

Values are expressed as means $\pm \mathrm{SD}, * \mathrm{P}<0.05$ is significant 
Table (5). Comparison between male and female patients according to different levels of TSH and thyroid antibodies.

\begin{tabular}{|c|c|c|c|c|c|}
\hline & \multicolumn{2}{|c|}{ Male } & \multicolumn{2}{|c|}{ Female } & \multirow[t]{2}{*}{$P$ value } \\
\hline & No & $\%$ & No & $\%$ & \\
\hline \multicolumn{6}{|l|}{ TSH } \\
\hline High & 27 & 60.0 & 25 & 71.4 & 0.3 \\
\hline Normal & 18 & 40.0 & 10 & 28.6 & \\
\hline \multicolumn{6}{|l|}{ Anti -TG } \\
\hline Negative & 20 & 44.4 & 11 & 31.4 & 0.5 \\
\hline Borderline & 12 & 26.7 & 12 & 34.3 & \\
\hline Positive & 13 & 28.9 & 12 & 34.3 & \\
\hline \multicolumn{6}{|l|}{ Anti-TPO } \\
\hline Negative & 21 & 46.7 & 11 & 31.4 & 0.1 \\
\hline Borderline & 9 & 20.0 & 14 & 40.0 & \\
\hline Positive & 15 & 33.3 & 10 & 28.6 & \\
\hline
\end{tabular}

Values are expressed by frequency and percentage

Table (6). Comparison between patients and controls according to thyroid gland size and volume assessed by thyroid ultrasound.

\begin{tabular}{lllll}
\hline & & Case (No=80) & Control (No=50) & P-value \\
\hline \multirow{3}{*}{ Right Lobe dimensions } & Transverse (cm) & $1.6 \pm 0.3$ & $1.3 \pm 0.2$ & $<0.001^{*}$ \\
& Longitudinal (cm) & $1.5 \pm 0.3$ & $1.4 \pm 0.2$ & 0.3 \\
& Antero Posterior (cm) & $1.4 \pm 0.3$ & $1.5 \pm 0.2$ & 0.3 \\
& Transverse (cm) & $1.5 \pm 0.3$ & $1.3 \pm 0.2$ & $<0.001^{*}$ \\
Left Lobe dimensions & Longitudinal (cm) & $1.4 \pm 0.3$ & $1.4 \pm 0.2$ & 0.9 \\
Isthmus & Antero Posterior (cm) & $1.3 \pm 0.3$ & $1.4 \pm 0.1$ & 0.1 \\
Volume (ml) & & $0.4 \pm 0.1$ & $0.4 \pm 0.1$ & 0.2 \\
Nodule size $(\mathrm{cm})$ & & $3.4 \pm 1.5$ & $2.9 \pm 0.9$ & $0.046^{*}$ \\
\hline
\end{tabular}

Values are expressed as means $\pm \mathrm{SD}, * \mathrm{P}<0.05$ is significant

Table (7). Comparison between type ldiabetic patients and controls according to different ultrasound findings.

\begin{tabular}{|c|c|c|c|c|c|c|}
\hline & & Cas & & Cor & & P-value \\
\hline \multirow{2}{*}{ Texture } & Homogenous & 60 & $75 \%$ & 47 & $94 \%$ & \multirow{2}{*}{$0.008^{*}$} \\
\hline & Heterogeneous & 20 & $25 \%$ & 3 & $6 \%$ & \\
\hline \multirow{2}{*}{ Vascularity } & Increased & 40 & $50 \%$ & 6 & $12 \%$ & \multirow{2}{*}{$<0.001^{*}$} \\
\hline & Normal & 40 & $50 \%$ & 44 & $88 \%$ & \\
\hline \multirow{2}{*}{ Nodules } & Present & 7 & $8.8 \%$ & 2 & $4 \%$ & \multirow{2}{*}{0.5} \\
\hline & Absent & 73 & $91.3 \%$ & 48 & $96 \%$ & \\
\hline \multirow{2}{*}{$\begin{array}{l}\text { Nodules } \\
\text { number }\end{array}$} & Single & 5 & $71.4 \%$ & 1 & $50 \%$ & \multirow{2}{*}{1} \\
\hline & Multiple & 2 & $28.6 \%$ & 1 & $50 \%$ & \\
\hline \multirow{2}{*}{ Calcification } & Present & 2 & $2.5 \%$ & 0 & 0 & \multirow{2}{*}{0.5} \\
\hline & Absent & 78 & $97.5 \%$ & 50 & $100 \%$ & \\
\hline \multirow{2}{*}{ Conclusion } & Abnormal & 20 & $25 \%$ & 3 & $6 \%$ & \multirow{2}{*}{$0.008^{*}$} \\
\hline & Normal & 66 & $75 \%$ & 47 & $94 \%$ & \\
\hline
\end{tabular}

Values are expressed as frequency, percentage and means $\pm \mathrm{SD},{ }^{*} \mathrm{P}<0.05$ is significant 
Table (8). Comparison between different levels of anti-thyroid Abs, TSH in type 1 diabetic patients according to thyroid texture and vascularity.

\begin{tabular}{|c|c|c|c|c|c|}
\hline & \multicolumn{5}{|c|}{ Thyroid texture } \\
\hline & \multicolumn{2}{|c|}{ Homogenous } & \multicolumn{2}{|c|}{ Heterogeneous } & p-value \\
\hline \multirow[t]{2}{*}{ Anti-TG } & \multicolumn{2}{|c|}{$354.6 \pm 370.1$} & \multicolumn{2}{|c|}{$471.7 \pm 459.4$} & 0.3 \\
\hline & No & $\%$ & No & $\%$ & \\
\hline Negative & 24 & $40 \%$ & 7 & $35 \%$ & \\
\hline Borderline & 18 & $30 \%$ & 6 & $30 \%$ & 0.9 \\
\hline Positive & 18 & $30 \%$ & 7 & $35 \%$ & \\
\hline Anti -TPO & \multicolumn{2}{|c|}{$221.7 \pm 257.5$} & \multicolumn{2}{|c|}{$315.6 \pm 339.8$} & 0.3 \\
\hline Negative & 25 & $41.7 \%$ & 7 & $25 \%$ & \\
\hline Borderline & 18 & $30.0 \%$ & 5 & $25 \%$ & 0.6 \\
\hline Positive & 17 & $28.3 \%$ & 8 & $40 \%$ & \\
\hline TSH & \multicolumn{2}{|c|}{$9.1 \pm 5.0$} & \multicolumn{2}{|c|}{$10.5+5.4$} & 0.3 \\
\hline Abnormal & 37 & $61.7 \%$ & 15 & $75 \%$ & 0.4 \\
\hline \multirow[t]{3}{*}{ Normal } & 23 & $38.3 \%$ & 5 & $25 \%$ & \\
\hline & \multicolumn{5}{|c|}{ Vascularity } \\
\hline & \multicolumn{2}{|c|}{ Increased } & \multicolumn{2}{|c|}{ Normal } & P value \\
\hline Anti -TG & \multicolumn{2}{|c|}{$440.2 \pm 407.9$} & \multicolumn{2}{|c|}{$327.6 \pm 377.3$} & 0.4 \\
\hline Anti-TPO & \multicolumn{2}{|c|}{$287.3 \pm 299.5$} & \multicolumn{2}{|c|}{$203.1 \pm 258.1$} & 0.4 \\
\hline TSH & \multicolumn{2}{|c|}{$10.2 \pm 5.2$} & \multicolumn{2}{|c|}{$8.7 \pm 5.1$} & 0.2 \\
\hline
\end{tabular}

Values are expressed as frequency, percentage and means \pm SD

Table (9). Correlations of anti-TG and anti-TPO with different patients' parameters.

\begin{tabular}{lllll}
\hline & Anti - TG & & Anti-TPO & P value \\
\cline { 2 - 5 } & r & P value & r & 0.11 \\
\hline Age (yrs) & -0.19 & 0.10 & -0.18 & 0.91 \\
Duration DM (yrs) & -0.04 & 0.74 & -0.02 & 0.43 \\
BMI $\left(\mathrm{kg} / \mathrm{m}^{2}\right.$ ) & 0.08 & 0.46 & 0.09 & 0.14 \\
HbA1c \% & 0.13 & 0.26 & 0.17 & $<0.001^{*}$ \\
Free T3 & -0.66 & $<0.001$ & -0.67 & $<0.001^{*}$ \\
Free T4 & -0.76 & $<0.001$ & -0.77 & $<0.001^{*}$ \\
TSH & 0.83 & $<0.001$ & 0.84 & 0.50 \\
Gland volume (ml) & -0.07 & 0.53 & -0.08 & \\
\hline
\end{tabular}

$\mathrm{r}=$ Spearman correlation coefficient, ${ }^{*} \mathrm{P}$ value is statistically significant

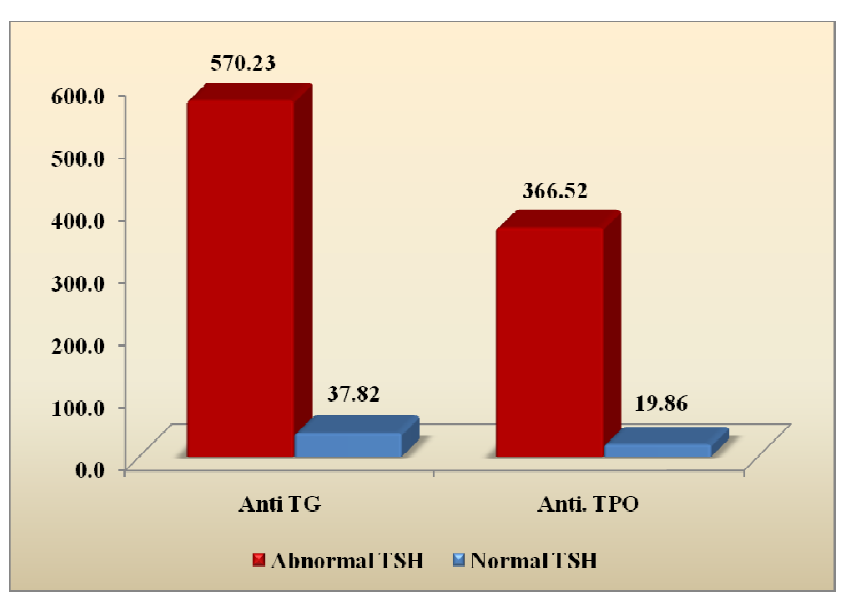

Fig. (1). Levels of thyroid Abs in type 1 diabetic patients in relation to normal and abnormal TSH levels.

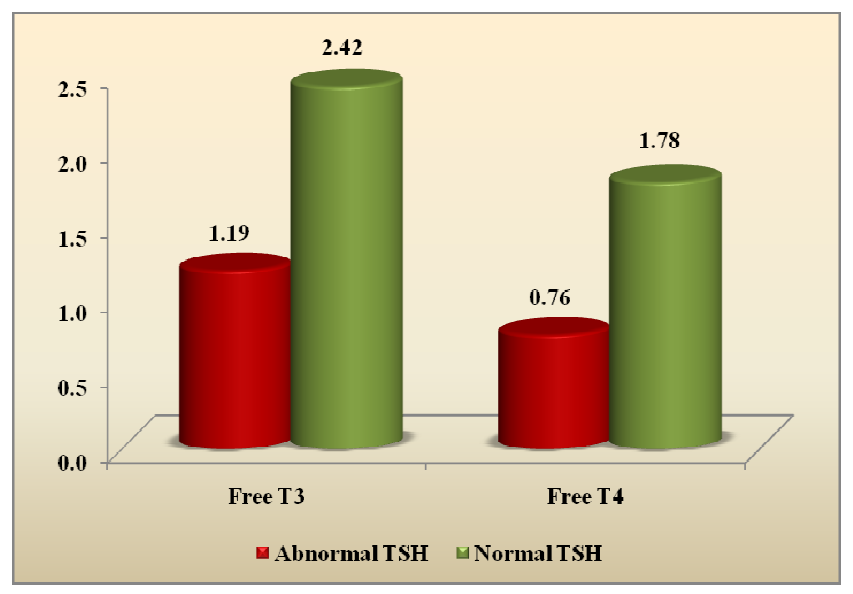

Fig. (2). Free T3, Free T4 levels in patients with type 1 DM in relation to normal and abnormal TSH levels. 


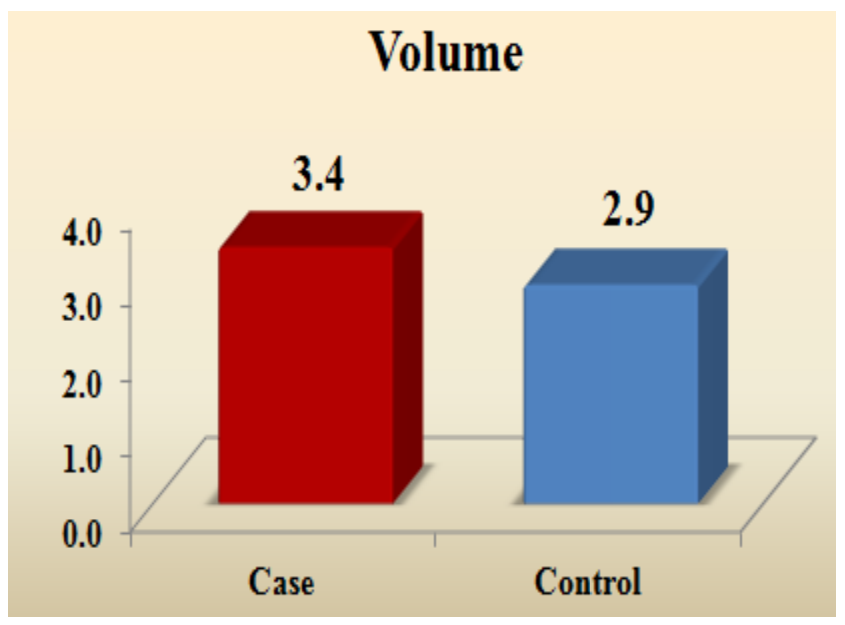

Fig. (3). Thyroid gland volume in case and control group.

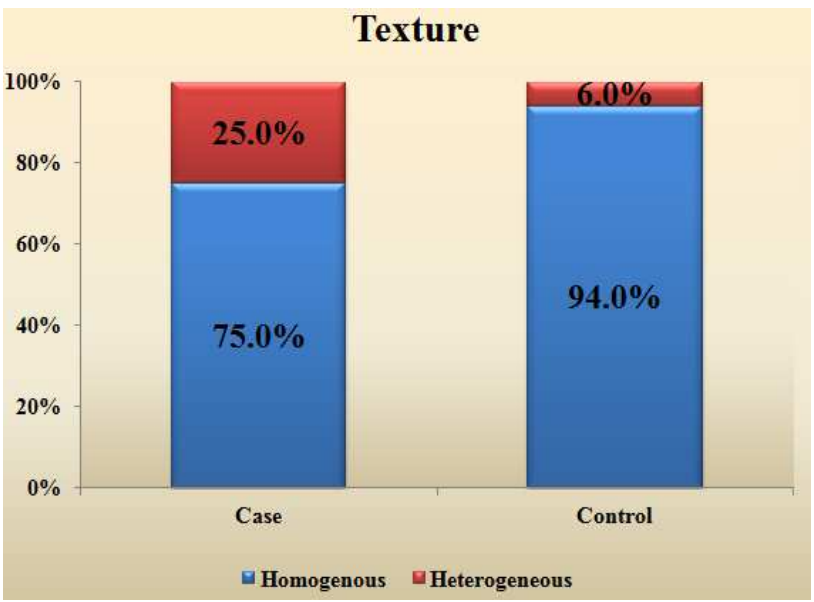

Fig. (4). Thyroid gland texture in case and control group.

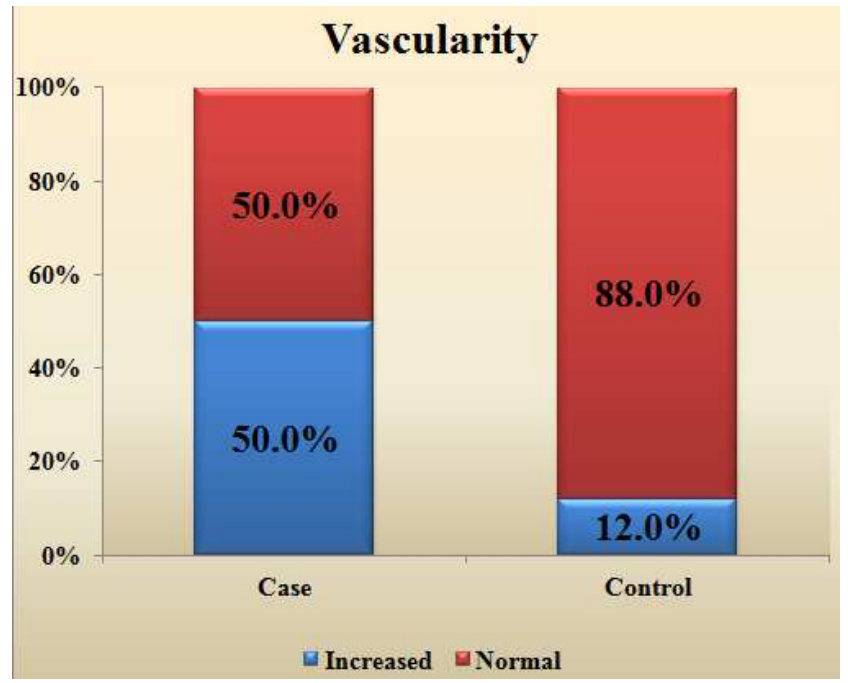

Fig. (5). Thyroid gland vascularity in case and control group.

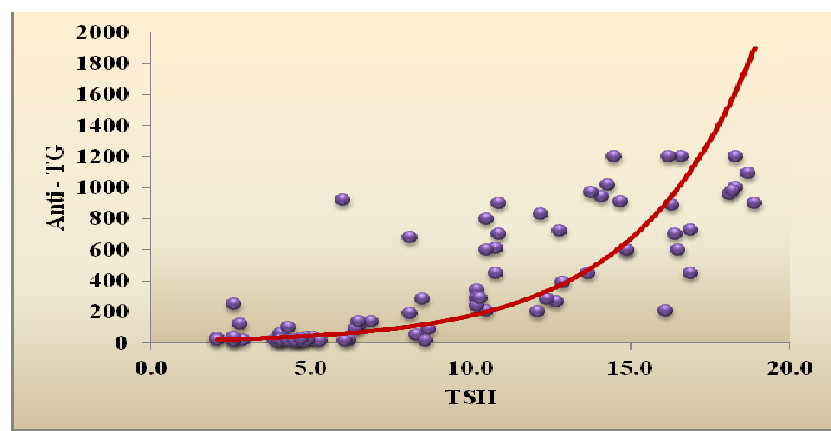

Fig. (6). Scatter plot graph shows the positive correlation between anti-TG and TSH.

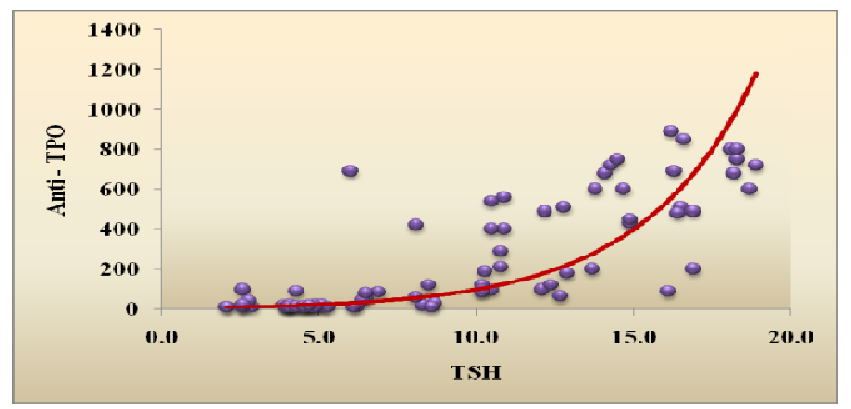

Fig. (7). Scatter plot graph shows the positive correlation between anti-TPO and TSH.

\section{Discussion}

In this study, increased TSH levels were present in 52 patients out of $80(65 \%)$ with mean $(12.37 \pm 3.9)$. Increased TSH levels were associated with significant decrease in FT3 and FT4 and significant increase in thyroid Abs levels, $\mathrm{P}<0.001$. The incidence of thyroid dysfunction in our study was higher than the study done by Hansen et al [11] who found 5\% of type 1 diabetic patients had thyroid dysfunction which increased to $8 \%$ after 3 years follow up. Also the study done by Perros et al. [21] reported the overall incidence of thyroid dysfunction $13.4 \%$ in diabetic patients and $31.4 \%$ in type 1 diabetic females.

In this study, we found $31.3 \%$ of our patients had positive anti-TG and anti-TPO levels. Increased levels of anti-TPO and anti-TG were associated with increased TSH levels which was statistically significant different when compared with patients with normal TSH levels. This finding was in agreement with Sharifi et al. [22] who found $39.6 \%$ of the Iranian type 1 diabetic patients had positive anti-TPO and $30 \%$ had positive anti-TG and also was associated with high TSH levels. Also a high prevalence of anti-TPO $35 \%$ was documented in American Hispanic patients [23]. The study done by Ghawil et al. [24] documented positive anti-TPO in $23.4 \%$ type 1 diabetic Libyan subjects and $7 \%$ had positive TG antibodies. Hansen et al [11] reported equal frequency directed against anti- TG and anti-TPO with prevalence $13 \%$ in anti-TPO and $14 \%$ in anti-TG in type 1 diabetic patients. In Brazil, Mantovani et al. [6] found positive anti-TPO levels in $16.7 \%$ Brazilian type 1 diabetic patients. In Egyptian studies, Omar et al. [25] found only $12 \%$ of patients had positive anti-TPO and 
was associated by $50 \%$ increase in the $\mathrm{TSH}$ level and Metwalley et al. [26] found positive anti-TPO in 9.5\% and positive anti-TG in $6.3 \%$ in patients lives in Upper Egypt. The different results in the prevalence of thyroid antibodies in previous studies may be related to difference in patient number, age, duration of diabetes, methodology used and patient ethnicity [10].

The mechanism underlying the association between AITD and T1DM is still controversial [27] but there is increasing evidence concerning common susceptibility genes that could be involved in this association as HLA [28], CTLA-4 [29], PTPN22 [30] and FOXP3 genes [31].

The association between positive serum anti-TPO and antiTG antibodies and high TSH levels also reported by previous studies $[3,32,33]$ and they demonstrated that TSH levels increase proportionally with the degree of positivity of thyroid antibodies. This association may be due to destruction of the thyroid gland by anti-TPO directly or indirectly through thyroid-infiltrating $\mathrm{T}$ cells associated auto antibodies [3].

Autoimmune endocrine disorders are mostly seen in females [34]. Anti-TPO usually presents in inheritable autosomal pattern in females not males [35]. Our results showed that females more frequently associated with increased TSH and thyroid antibodies but with no significant difference between both sex and this was in agreement with previous studies $[11,22,36]$. In contrast, Kordonouri et al [33] reported increased frequency of anti-TPO in females $19.9 \%$ versus $11.6 \%$ in males and $18.6 \%$ anti-TG in females versus $11 \%$ in males with significant difference between both them.

Although the duration of diabetes in our patients ranged between 0.25 and 23 years with high prevalence of thyroid Abs (31.3\%), but we did not find significant correlation between them. This was in agreement with Hansen et al [11] who did not find significant correlation between thyroid antibodies and duration of diabetes. In contrast, Sharifi et al [22] found significant positive anti- TPO titer in patients with longer duration of diabetes but not with anti-TG. Also we did not find significant correlation between thyroid antibodies and $\mathrm{HbAlc}$ as a measure for diabetic control and this was in agreement with other studies [3, 11, 25, 36].

We found significant positive correlation between thyroid antibodies and TSH levels with $\mathrm{P}$-value $<0.001$ and significant negative correlation with Free T3, Free T4 levels with $\mathrm{P}$-value $<0.001$, this was also reported by previous studies [22, 32]. This means that type 1 diabetic patients with positive anti TPO which is highly suggestive of AITD is vulnerable to develop thyroid dysfunction [37]. Glastras et al [38] found patients with type 1diabetes had positive thyroid antibodies were more likely to develop thyroid disease $18 \%$ more than patients who were negative after 13 years follow up therefore they recommended screening for thyroid antibody at the time of diagnosis followed by screening the TSH level every 2-3 years.

In our study, there was high prevalence of morphological abnormalities demonstrated by thyroid US in type 1 diabetic patients $(20 \%)$ compared to the control group $(6 \%)$ which was statistically significant, $\mathrm{P}=0.008$. This was in agreement with Hansen et al. [39] who found morphological abnormalities in the thyroid gland in type I diabetic patients $42 \%$ compared to controls $11 \%$. This finding is not supported by Darendeliler et al. [40] who found US abnormalities in only 2 of 83 young diabetics.

There was significant increase in the volume of the thyroid gland in type 1 diabetic patients compared to controls, $\mathrm{P}=$ 0.046 but this was not significantly correlated with thyroid antibodies or TSH levels. This was in agreement with Bianchi et al. [41] who reported increased thyroid volume in adult type 1 diabetic patients compared to age and sex matched controls and was not significantly correlated with thyroid antibodies or TSH levels. Also Junik et al [42] found significant increase in gland volume in type 1 diabetic patients, $\mathrm{P}<0.05$ compared to controls. In contrast Hansen et al. [39] found overall increase in the gland volume in type 1 diabetic patients compared to the control group but this was not significant. The increased gland volume could be an expression of ongoing autoimmune process causing alterations in the thyroid gland in many of the diabetics [41, 43].

One of the dominant US findings in our study was the significant difference in texture echogenicity. We found heterogenous hypoechogenic texture in $25 \%$ diabetic patients versus $6 \%$ in controls which was statistically significant different with P-value $=0.008$ this was in agreement with Hansen et al. [39] who found high frequency of US hypoechogenicity in type 1 diabetics compared to controls (40\% versus $8 \%$ ), in contrast Junik et al [42] did not find any difference in echogenicity between type 1 diabetic patients and controls. Marcocci and his co-workers [44] reported prevalence of diffuse hypoechogenicity $20 \%$ in patients diagnosed with autoimmune thyroid disease by thyroid antibodies and they assumed that this finding is indicative of autoimmune affection of the thyroid gland and may be a valuable marker in autoimmune thyroid disease predicting the development of hypothyroidism. However US finding of hypoechogenicity is also seen in other thyroid disorders as Graves' disease [45].

Although Color Doppler study usually show normal or decreased flow as reported by Pedersen et al. [12] we found significant increase in vascularity in 40 patients which represent $50 \%$ versus $12 \%$ in controls, P-value $<0.001$. These ultrasound findings were not correlated with thyroid antibodies and TSH levels.

In conclusion, our study revealed high prevalence of thyroid Abs 31.3\% and thyroid dysfunction 65\% which significantly correlated to each other in type 1 diabetic patients. We also found morphological abnormalities in the form of increased gland volume, increased vascularity and heterogenous hypoechogenic texture in type 1 diabetic patients compared to controls which may be an early marker of autoimmune thyroid disease. Therefore, we recommend screening type $1 \mathrm{DM}$ patients for thyroid dysfunction and performing thyroid ultrasound for early detection of any 
morphological abnormality and if there is thyroid dysfunction or US abnormality further measurement of thyroid antibodies to diagnose AITD and follow-up every year by serum TSH level to prevent progression and associated metabolic complications of the disease.

\section{References}

[1] Liese AD, D'Agostino RB Jr, Hamman RF, Kilgo PD, Lawrence JM, Liu LL, et al. The burden of diabetes mellitus among US youth: prevalence estimates from the search for Diabetes in Youth Study. Pediatrics 2006;118:1510-1518.

[2] Dretzke J, Cummins C, Sandercock J, Fry-Smith A, Barrett T, Burls A. Autoantibody testing in children with newly diagnosed type 1 diabetes mellitus. Health Technol Assess 2004;8(22):1-183.

[3] Kakleas K, Paschali E, Kefalas N, Fotinou Aspasia, Kanariou $\mathrm{M}$, et al. Factors for thyroid autoimmunity in children and adolescents with type 1 diabetes mellitus. Ups J Med Sci 2009; $114: 214-20$

[4] Severinski S, Banac S, Severinski NS, Ahel V, Cvijović K. Epidemiology and clinical characteristics of thyroid dysfunction in children and adolescents with type 1 diabetes. Coll Antropol 2009;33:273-9.

[5] Lorini R, d'Annunzio G, Vitali L, Scaramuzza A. IDDM and autoimmune thyroid disease in the pediatric age group. $J$ Pediatr Endocrinol Metab 1996;9:89-94.

[6] Mantovani RM, Mantovani LM, Dias VM. Thyroid autoimmunity in children and adolescents with type 1 diabetes mellitus: Prevalence and risk factors. J Pediatr Endocrinol Metab. 2007;20:669-75.

[7] Kadiyala, R.; Peter, R.\& Okosieme OE. Thyroid dysfunction in patients with diabetes:clinical implications and screening strategies. Int J Clin Pract 2010;64:1130-1139

[8] Leong KS, Wallymahmed M, Wilding J, MacFarlane I. Clinical presentation of thyroid dysfunction and Addison's disease in young adults with type 1 diabetes.Postgraduate Medical Journal. 1999;75:467-470.

[9] Samaneh Khanpour Ardestani, Ammar Hassanzadeh Keshteli, Noushin Khalili, Mahin Hashemipour, Reihaneh Barekatain. Thyroid Disorders in Children and Adolescents with Type 1 Diabetes Mellitus in Isfahan, Iran. Iran J Pediatr 2011; 21:502-508

[10] Hage M, Zantout MS, Azar ST. Thyroid disorders and diabetes mellitus. J Thyroid Res 2011;10:1-7.

[11] Hansen D, Bennedbaek FN, Høier-Madsen M, Hegedüs L, Jacobsen BB.: A prospective study of thyroid function, morphology and autoimmunity in young patients with type 1 diabetes. Eur J Endocrinol 2003; 148(2):245-51.

[12] Pedersen OM, Aardal NP, Larssen TB, et al. The value of ultrasonography in predicting autoimmune thyroid disease. Thyroid 2000;10:251.

[13] American Diabetes Association. Standards of medical care in diabetes. Diabetes Care 2012;35(1):11-63.
[14] Expert Committee on the Diagnosis and Classification of Diabetes Mellitus. Diabetes Care 2003; 26:5-20.

[15] Spencer CA. Clinical Chemistry,"Interlaboratory/Intermethod differences in Functional Sensitivity of Immunometric Assays of Thyrotropin (TSH) and Impact on Reliability of Measurement of Subnormal Concentrations of TSH"1995;41:367.

[16] Sati, C., Chattor, A.J., Watts, N. Fundamentals of Clinical Chemistry. Ed. Tietz, N.W. 3rd Ed:586. Saunders Press Phila 1987.

[17] Midgeley John, EM. "Direct and Indirect Free Thyroxine Assay Methods. Theory and Practice". Clin. Chem. 2001;47:1353-1363.

[18] Czarnocka, B., Ruf, J., Ferrand, M. Purification of the human thyroid peroxidase and its identification as the microsomal antigen involved in autoimmune thyroid diseases. FEBS Lett. 1985; 190:147- 152 .

[19] Norbert G. Dietmar K and Thomas R. Radiologic evaluation of the neck sonography of the thyroid and parathyroid glands. Radiologic clinics of north America 2000;38:1131.

[20] Gomez JM, Maravall FJ, Gomez N, Guma A, Soler J. Determinants of thyroid volume as measured by ultrasonography in healthy adults randomly selected. Clin Endocrinol (Oxf) 2000;53:629-34.

[21] Perros P, McCrimmon RJ, Shaw G, Frier BM. Frequency of thyroid dysfunction in diabetic patients: value of annual screening. Diabet Med 1995;12:622-627.

[22] Sharifi F, Ghasemi L, Mousavinasab N. Thyroid Function and anti-thyroid antibodies in Iranian patients with type 1 diabetes mellitus: influences of age and sex. Iran J Allergy Asthma Immunol 2008;7:31-6.

[23] Frasier SD, Penny R, Snyder R, Goldstein I, Graves D. Antithyroid antibodies in Hispanic patients with type I diabetes mellitus. Prevalence and significance. Am J Dis Child 1986;140:1278-80.

[24] Ghawil M, Tonutti E, Abusrewil S, Visentini D, Hadeed I, Miotti V, et al. Autoimmune thyroid disease in Libyan children and young adults with type 1 diabetes mellitus. Eur J Pediatr. 2011;170:983-7.

[25] Omar M.A, Rizk M.M, ElKafoury A.A, Doaa K. Screening for thyroid disease among children and adolescents with type 1 diabetes mellitus. Alexandria Journal of Medicine (2014) 50, $77-82$.

[26] Metwalley KA, El-Saied AA. Thyroid abnormalities in Egyptian children and adolescents with type 1 diabetes mellitus: A single center study from Upper Egypt. Indian J Endocrinol Metab. 2014; 18: 637-641.

[27] Vaidya B, Pearce S. The emerging role of the CTLA-4 gene in autoimmune endocrinopathies. Eur J Endocrinol. 2004;150:619-26.

[28] Golden B, Levin L, Ban Y, Concepcion E, Greenberg DA, Tomer Y. "Genetic analysis of families with autoimmune diabetes and thyroiditis: evidence for common and unique genes," Journal of Clinical Endocrinology and Metabolism 2005; 90:4904-4911. 
[29] Ikegami H, Awata T, Kawasaki E, Kobayashi T, Maruyama T, Nakanishi K, et al. The association of CTLA4 polymorphism with type 1 diabetes is concentrated in patients complicated with autoimmune thyroid disease: a multicenter collaborative study in Japan. Journal of Clinical Endocrinology and Metabolism 2006;91:1087-1092.

[30] Kawasaki E, Awata T, Ikegami H, Kobayashi T, Maruyama T, Nakanishi K, et al., Systematic search for single nucleotide polymorphisms in a lymphoid tyrosine phosphatase gene (PTPN22): association between a promoter polymorphism and type 1 diabetes in Asian populations. American Journal of Medical Genetics 2006;140:586-593.

[31] Villano MJB, Huber AK, Greenberg DA, Golden BK, Concepcion E, Tomer Y. Autoimmune thyroiditis and diabetes: dissecting the joint genetic susceptibility in a large cohort of multiplex families. Journal of Clinical Endocrinology and Metabolism 2009;94:1458-1466.

[32] Ghoraishian SM , Moghaddam SHH, Ardekani MA. Relationship between Anti-Thyroid Peroxidase Antibody and Thyroid Function Test. Iran.J.Immunol.2006;3:146-149.

[33] Kordonouri O, Hartmann R, Deiss D, Wilms M, Gru"tersKieslich A. Natural course of autoimmune thyroiditis in type 1 diabetes: association with gender, age, diabetes duration, and Puberty. Arch Dis Child 2005;90:411-414.

[34] Barker JM, Yu J, Yu L, Wang J, Miao D, Bao F, et al. Autoantibody "subspecificity" in type 1 diabetes: risk for organ-specific autoimmunity clusters in distinct groups. Diabetes Care 2005; 28:850-5.

[35] Phillips D, Prentice L, Upadhyaya M, Lunt P, Chamberlain S, Roberts DF, et al. Autosomal dominant inheritance of autoantibodies to thyroid peroxidase and thyroglobulin-studies in families not selected for autoimmune thyroid disease. J Clin Endocrinol Metab 1991;72:973-5.

[36] Prazny M, Skrha J, Limanova Z, Vanickova Z, Hilgertova J, Prazna J, et al. Screening for associated autoimmunity in type 1 diabetes mellitus with respect to diabetes control. Physiol Res 2005;54:41-8.
[37] Kordonouri O, Klinghammer A, Lang EB, Gruters-Kieslich A, Grabert M, Holl R. Thyroid autoimmunity in children and adolescents with type 1 diabetes: a multicenter survery. Diabetes Care 2002;25:1346-50.

[38] Glastras S, Craig ME, Verge CF, Chan AK, Cusumano JM, Donaghue KC. The role of autoimmunity at diagnosis of type 1 diabetes in the development of thyroid and celiac disease and microvascular complications. Diabetes Care 2005;28:2170-2175.

[39] Hansen D, Bennedbæk FNL, Hansen LK, Høier-Madsen M, Jacobsen BB, Hegedus L. Thyroid function, morphology and autoimmunity in young patients with insulin-dependent diabetes mellitus .European Journal of Endocrinology 1999;140:512-518.

[40] Darendeliler FF, Kadioglu A, Firdevs B, Bundak R, Gu“no“z H,Saka $\mathrm{N}$ et al. Thyroid ultrasound in IDDM. Journal of Pediatric Endocrinology 1994;7:33-37.

[41] Bianchi G, Montanari P, Fabbri A, Gamberini A, Zoli M, Marchesini G. Thyroid volume in type 1 diabetes patients without overt thyroid disease. Acta Diabetologica 1995;32 49-52.

[42] Junik R, Kozinski M, Debska K. Thyroid Ultrasound in Diabetic Patients without Overt Thyroid Disease Acta Radiol 2006;47:687-691.

[43] Gomez JM, Maravall FJ, Guma A, Abos R, Soler J, Fernandez-Castaner M. Thyroid volume as measured by ultrasonography in patients with type 1 diabetes mellitus without thyroid dysfunction. Horm Metab Res 2003;35:48691.

[44] Marcocci C, Vitti P, Cetani F, Catalano F, Concetti R \& Pinchera A. Thyroid ultrasonography helps to identify patients with diffuse lymphocytic thyroiditis who are prone to develop hypothyroidism. Journal of Clinical Endocrinology and Metabolism 199172 209-213.

[45] Sostre S, Reyes MM. Sonographic diagnosis and grading of Hashimoto's thyroiditis. Journal of Endocrinological Investigation 1991;14:115-121. 